\title{
Dibalik Nama Sidoarjo
}

\author{
NUR INDAH SAFIRA \\ Universitas Nahdlatul Ulama Sidoarjo \\ Email : nurindahsafira2000
}

\section{Pengantar}

kabupaten di sidoarjo merupakan salah satu pondasi untuk warga pesisir. Pentinganya keberadaan sidoarjo bagi jawa timur, terbukti juga dari bergabungnya sidoarjo dalam satu kesatuanwilayah pembangunan (SWP) jawa timur yang dikenal sebagai gerbang kertasusila (Hendra Sukmana 2016). Kabupaten sidoarjo juga terkenal dengan nama kota delta karena dalam sejarah kota sidoarjo dikelilingi oleh lautan. Lautan yang memang pada dahulu tidak ada sedikit pun rumah atau pedesaan. Pada masa itu yang menjadikan kota yang dahulunya pesisir menjadi seperti saat ini adalah para ulama' dan kyai. Sehinggaa pada saat ini kota sidoarjo menjadi kota yang asri dan indah.

\section{Asal usul sidoarjo}

Sidoarjo adalah kota yang dikenal sebagai lambang udang dan bandeng. Sidoarjo memiliki luas sekitar 591,59 km. sidoarjo dulu dikenal sebagai pusat kerajaan jenggolo pada masa kolonialisme hindia belanda, dahulu kota sidoarjo dikenal dengan sidokare sido $=$ jadi kare $=$ kari karena intonasi warga sedikit jelek sehingga nama sidokare berubah menjadi sidoarjo.

Daerah sidokare dahulu dipimpin oleh patih yang bernama R.NG.DJOOHARJO tinggal di sebuah kampung pucang anomyang dibantu oleh seseorang wedana yaitu bagus ranuwiryo yang tinggal dikampung pangabahan pada tahun 1859. Berdasarkan keputusan hindia belanda, pada tanggal 31 januari 1859 kabupaten Surabaya dibagi meenjadi 2 kabupaten Surabaya dan kabupaten sidokare. Sidoarjo juga terkenal dengan sebutan kota delta karena ada diantara 2 sungai besar pecahan dari sungai brantas yaitu sungai mas dan sungai porong. Sidoarjo berada di selatan Surabaya, secara geografis dua kota ini seolah menyatu. 


\section{Arti logo sidoarjo}

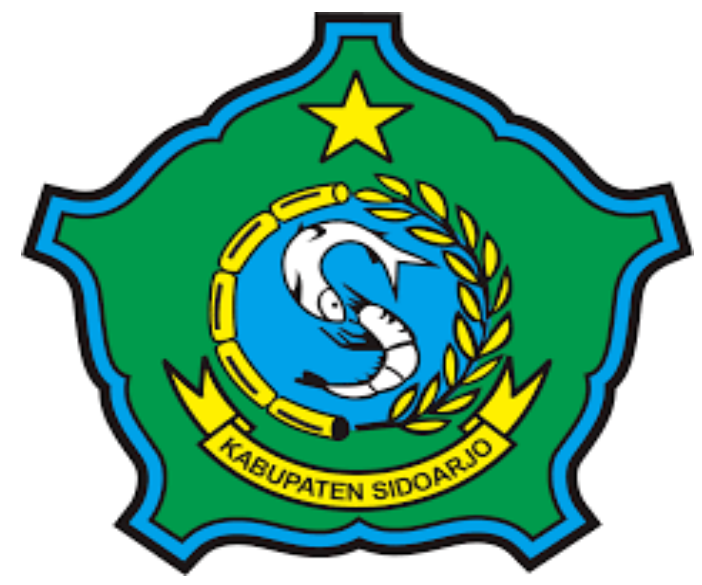

- Sebuah segilima beraturan yang sisinya berbentuk kurung kurawal Melambangkan: falsafah pancasila yang juga mengandung arti bahwa rakyatdaerah kabupaten sidoarjo telah mentrapkan ajaran pancasila dengan tertip dan pasti.

- Sebuh bintang bersudut lima

Melambangkan: ketuhanan yang maha esa yang menggambarkan kehidupan ber ketuhanan atau beragama dari rakyat daerah kabupaten sidoarjo.

- Setangkai padi, delapan belas butir dan sebatang tebu lima ruas dengan bentuk bulat

Melambangkan: hasil bumi yang paling penting dalam kabupaten sidoarjo. Sedangkan bentuk yang bulat dari padi dan tebu tersebut menggambarkan kebulatan tekat untuk membangun masyarakat yang adil dan makmur 18 (delapan belas) butir padi menunjukkan banyaknya kecamatan dalam daerah kabupaten sidoarjo.

- Ikan bandeng dan ikan udang membentuk huruf "S"

Melambangkan : hasil tambak dalam daerah kabupaten sidoarjo.

Bentuk huruf "S" dari ikan bandeng dan udang tersebut menunjukkan huruf pertama dari sidoarjo. (www.sidoarjokab.go.id) 


\section{Slogan/moto sidoarjo}

"SIDOARJO PERMAI BERSIH HATINYA"

(pertanian maju, Andalan industrI, Bersih, Rapi, Serasi, Hijau, Sehat, indah dan yaman)

Artinya, kabupaten sidoarjo merupakan daerah pertanian yang subur sebagai lumbunpangan, mempertahankan pertanian yang maju agar bisa swasembada pangan dengan cara identivikasi pertanian dan menggunakan mekanisasi teknologi tepat guna, disamping itumendorong perkembangan industri yang semakin meningkat, maka kedua hal ini harusberkembang secara serasi, selain itu masyarakat kabupaten sidoarjo berbudaya hidup dengan lingkungan yang bersih , rapi, serasi, hijau, sehat, indah, dan nyaman.(www.sidoarjokab.go.id)

\section{perkembangan perekonomian di sidoarjo tahun 2011- 2018}

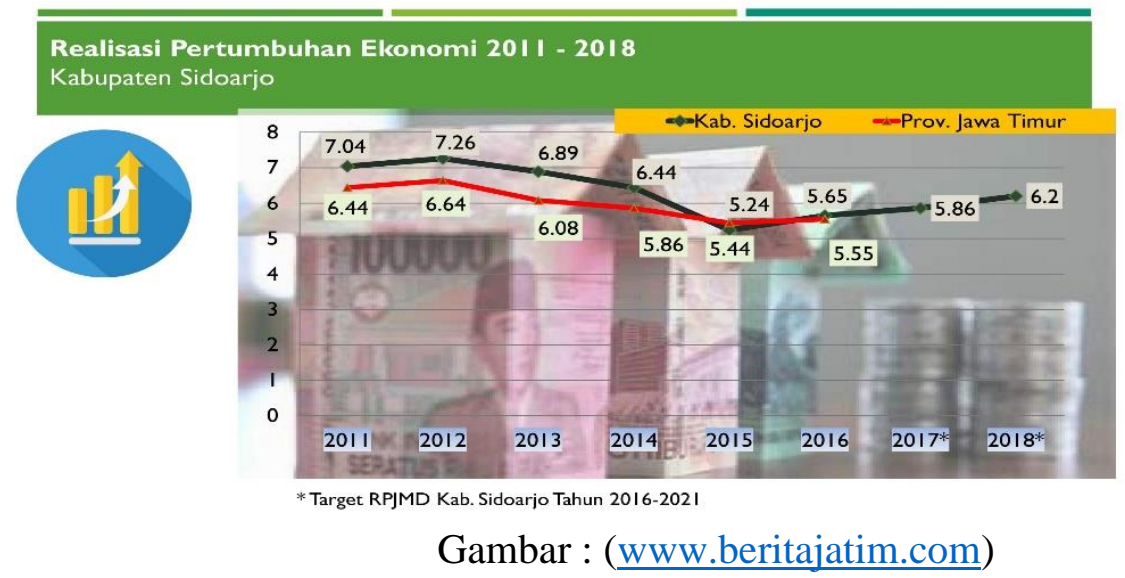

Pertumbuhan ekonomi di setiap kota memang berbeda- beda, ada yang semakin baik adapula yang semakin buruk, namun untuk daerah sidoarjo, perkembangan ekonomi semakin baik dan bagus. Berita tersebut ditegaskan oleh bupati sidoarjo saifull illah

Pada tahun 2006 sidoarjo sempat mengalami keterpurukan akibat bencana lumpur lapindo. Banyak perusahaan yang mengalami kebangkrutan bahkan sampai ada yang gulung tikar, namun pada 2010 sidoarjo bangkit dan pertumbuhan ekonominya semakin baik. Saiful mengaku

pertumbuhan ekonomi sidoarjo mencapai angka $7,13 \%$ di atas rata-rata nasional. Ia juga mengaku sidoarjo pernah menjadi juara umum "INVESTMENT AWARD" dan total 38 kabupaten sejawa timur yang diberikan oleh gubenur jatim.(www.beritajatim.com) 


\section{Masakan khas sidoarjo}

Hampir sama seperti daerah lain di Indonesia, kabupaten sidoarjo juga memiliki makanan khasnya sendiri yang menjadikan ciri khas kabupaten sidoarjo ini, harga yang terjangkau dan bisa cukup bertahan lama, cocok dijadikan oleh-oleh khas sidoarjo. Berikut beberapa makanan khas sidoarjo yang biasanya mudah untuk ditemui.

1. Bandeng asap

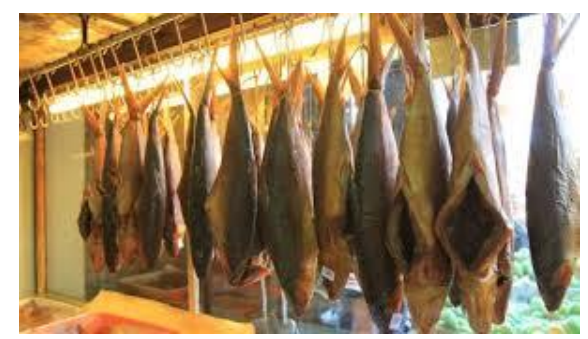

Gambar : www.putratrevel.net

Makanan khas sidoarjo ini adalah ikan bandeng asap. Perlu diketahui sidoarjo merupakan kota tambak yang menjadikan salah satu pengahasilan ikan bandeng terbesar di jawa timur. Oleh karena itu masyarakat sidoarjo memasukkan ikan ini dalam lambang kota sidoarjo . karna stok bandeng di sidoarjo sangat melimpah. Cara membuatan bandeng asap juga tidak terlalu sulit. Dan rasanya pun sangat memuaskan lidah.

2. Otak-otak bandeng

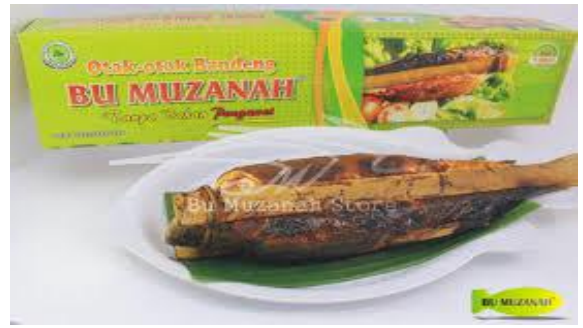

Gambar : www.putratravel.net

Sekali lagi olahan khas sidoarjo ini merupakan olahan dari bandeng, otak-otak yang dibuat di sidoarjo menngunakan isian dalam dengan kelapa yang di sangrai sampai kering yang dicampur dengan rempah-rempah serta kocookan telur. Aromanya gurih dan harum aromanya juga membuat godaan perut tidak tahan lagi untuk mencicipinya. 
3. Lontong kupang

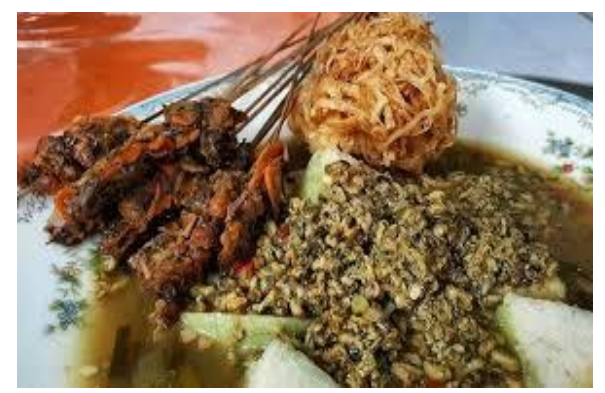

Gambar : www.putratravel.net

Jangan ngaku pernah ke sidoarjo kalo belum pernah makan lontong kupang, lontongnya sih gk jauh beda dengan lontong pada umumnya, hanya saja ada 3 bahan yang menjadikan kupang menjadi istimewa yakni kupang lento petis .Kuah lontong kupang terdiri dari petis khas sidoarjo dengan cita rasa pedas,

\section{Jumlah kenaikan penduduk sidoarjo tahun 2018}

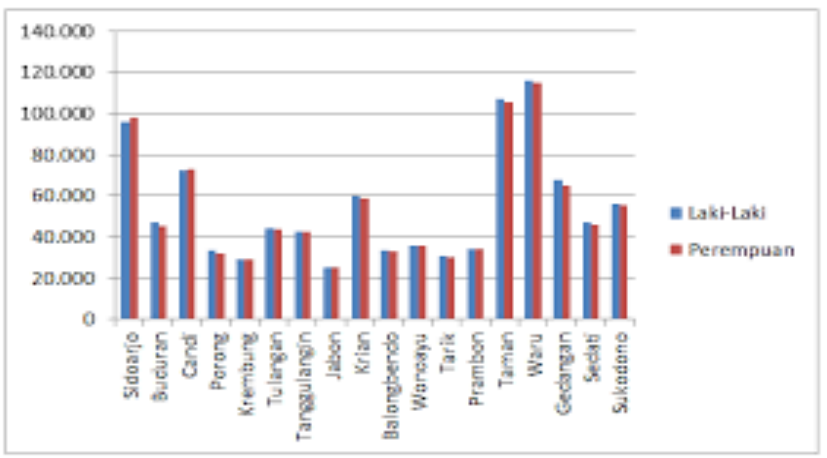

Gambar :www.sidoarjokab.go.id

Jumblah kenaikan penduduk sidoarjo sangat pesat di beberapa daerah juga memiliki kenaikan yang sangat pesat juga, penduduk yang paling padat terletak di daerah kecamatan waru. 


\section{Referensi}

- Kamis. 27.02 .00

Sid.sidoarjokab.go.id

- Kamis.27. 02.00

Azizah dinda p. 2016 "SIDOARJO KOTA

DELTA".Umm.ac.id/2016/08/10/76/)

- Kamis. 27. 02.00

putratravel.net/makanan-khas-sidoarjo

- Kamis 27.02.00 sidoarjokab.go.id/index.php?p=read\&id=4 


\section{"dibalik nama sidoarjo"}

1)pengantar/pembuka

a. latar belakang dibalik nama sidoarjo (what)

2) sejarah

a. asal usul sidoarjo (when)

b. arti logo sidoarjo (who)

c. slogan/moto sidoarjo (how)

3) ekonmi

a. perkembangan perekonomian di sidoarjo (why)

4) kuliner

a. masakan khas sidoarjo (where)

5) jumblah kenaikan penduduk sidoarjo (how much)

6) referensi 
